7. Chapman DG. Some properties of the hypergeometric distribution with applications to zoological sample censuses. UC publications in statistics, vol. 1 no. 7. Berkeley (CA): University of California Press; 1951.

8. Wittes JT. On the bias and estimated variance of Chapman's two-sample capture-recapture population estimate. Biometrics. 1972;28:592-7. http://dx.doi.org/10.2307/2556173

Address for correspondence: Etienne Gignoux, Médecins Sans Frontières, 78 Rue de Lausanne, CP 116, 1211 Geneva 21, Switzerland; email: etienne.gignoux@geneva.msf.org

\title{
Malformations Caused by Shuni Virus in Ruminants, Israel, 2014-2015
}

\section{Natalia Golender, ${ }^{1}$ Jacob Brenner, ${ }^{1}$ Motti Valdman, Yevgeny Khinich, Velizar Bumbarov, Alexander Panshin, Nir Edery, Shimon Pismanik, Adi Behar}

\author{
Author affiliations: Kimron Veterinary Institute, Bet Dagan, \\ Israel (N. Golender, J. Brenner, Y. Khinich, V. Bumbarov, \\ A. Panshin, N. Edery, A. Behar); Hachaklait, Caesarea, Israel \\ (M. Valdman); Israeli Veterinary Field Services, Gilboa, Israel \\ (S. Pismsanik)
}

\section{DOI: http://dx.doi.org/10.3201/eid2112.150804}

To the Editor: Viruses in the Simbu serogroup are arboviruses that cause abortion, stillbirth, and congenital abnormalities in domestic ruminants. Akabane virus (AKAV), Aino virus (AINV), and Schmallenberg virus are the most studied in this serogroup; Shuni, Sabo, Shamonda, and Sango viruses $(1,2)$ are examined less frequently. Until 2012, only AKAV had been associated with congenital abnormalities in Israel, although AINV had been identified serologically in dairy cow herds with no clinical signs in 2003 (3). Moreover, of 15 brain samples collected during February-October 2012 from adult cows with central nervous system manifestations, 6 were positive for AKAV by PCR.

In late December 2014, the Israeli Veterinary Field Services was notified of the appearance of arthrogryposishydranencephaly syndrome (1) in 2 herds of sheep in the villages of Yokneam and Sde Ya'akov, respectively; both villages are located in the Izre'el Valley, in Israel's northern valleys (online Technical Appendix Figure 1, http:// wwwnc.cdc.gov/EID/article/21/12/15-0804-Techapp.pdf), where several arboviral infections have occurred in recent decades. From our past experience (3), $\geq 1$ virus of the Sim-

${ }^{1}$ These authors contributed equally to this article. bu serogroup was suspected to have infected the ruminants, probably during August-October 2014.

We collected 27 samples of brain, placenta, spleen, lung, and blood (mixed with EDTA to prevent coagulation) from 15 sheep, goats, and cattle. Most samples were from the 2 affected flocks in the northern valley; a few were from ruminants in additional locations: Avadon, near Israel's border with Lebanon; Ein Hachoresh, near central Israel; and Hura, close to the Negev desert (online Technical Appendix Figure 1).

Of the 27 samples, 23 (85\%) were positive for Shuni virus (SHUV) by PCR (Table). SHUV, which had not been reported in Israel, was isolated from the brain and placenta of 1 malformed lamb (strain 2504/3/14; sample 11 in the Table). Moreover, partial nucleotide sequences of the small, medium, and large DNA segments $(580 / 850,4,320 / 4,326$, and $285 / 6,880 \mathrm{bp}$, respectively) were identified from 3 samples (strains Yokneam 2417/2/14 and 2504/3/14 and Hura 273/14 from samples 2, 11, and 9, respectively, in the Table; online Technical Appendix Figure 2). Sequence data obtained by conventional PCR in this study have been deposited into GenBank (accession nos. KP900863-5, KP900873-5, KP900879-80, and KP900884). Phylogenetic analysis of the samples showed that they were isolates of SHUV (online Technical Appendix Figure 2). Additional SHUV RNA-specific fragments were detected in pathologic samples from kids, lambs, and calves (Table). Full-genome sequences were not performed, although sequencing should be done when possible to determine precise origin of isolates.

For further testing, we inoculated homogenate material from 7 distinct malformations (samples 1, 2, 6, 8, 11, 12 , and 15 in the Table) into baby mice; only 1 family of baby mice inoculated intracerebrally with the SHUV isolate (sample 11 in the Table) exhibited characteristic neurologic signs of nervousness. PCR confirmed that SHUV caused the cerebral infections in these mice. The isolate was also suitable for further propagation in the Vero cell line (Table).

Our results showed the presence of SHUV in sheep in Israel during the winter of 2014-15 and suggest a northward expansion of SHUV from sub-Saharan Africa. Although SHUV was first isolated in the 1960s (2), its role as a pathogen has been shown only recently in its involvement in encephalitis in horses (4). We isolated SHUV from the pathologic fetal brain of a malformed lamb, an unusual laboratory finding because, although Simbu viruses are readily isolable from vectors or exposed animals during the 3 or 4 days of viremia, they are seldom isolable from pathologic specimens collected for study of congenital malformations. We deduce from the clinical evidence that malformations appear up to 6 months after infection with SHUV and after the virus has been eliminated from the host after immune 
Table. Summary of diagnostic and laboratory findings, animal species, sample materials, and region where samples were collected in the study of Shuni virus infection in ruminants, Israel, 2014-15*

\begin{tabular}{|c|c|c|c|c|c|c|c|}
\hline $\begin{array}{l}\text { Animal } \\
\text { no. }\end{array}$ & $\begin{array}{c}\text { Laboratory } \\
\text { no. }\end{array}$ & Species & Clinical manifestation & Region & PCR-positive sample & $\begin{array}{c}\text { Vero } \\
\text { isolation }\end{array}$ & $\begin{array}{c}\text { Virus isolation } \\
\text { in mice }\end{array}$ \\
\hline 1 & $2417 / 1 / 14$ & Sheep & Malformed, aborted fetus & Northern valley & Brain, placenta & Negative & Negative \\
\hline 2 & $2417 / 2 / 14$ & Sheep & Malformed, aborted fetus & Northern valley & Brain & Negative & Negative \\
\hline 3 & $267 / 2 / 14$ & Sheep & Malformed, aborted fetus & Northern valley & Brain & Not done & Not done \\
\hline 4 & $267 / 3 / 14$ & Sheep & Malformed, aborted fetus & Northern valley & Brain & Not done & Not done \\
\hline 5 & $267 / 4 / 14$ & Sheep & Malformed, aborted fetus & Northern valley & Brain & Not done & Not done \\
\hline 6 & $2498 / 1 / 14$ & Sheep & Weak lamb syndrome & Northern valley & Brain, EDTA-blood & Negative & Negative \\
\hline 7 & $2504 / 1 / 14$ & Sheep & Malformed aborted fetus & Northern valley & Brain & Not done & Not done \\
\hline 8 & $2504 / 2 / 14$ & Sheep & Malformed, aborted fetus & Northern valley & Brain, placenta & Negative & Negative \\
\hline 9 & $273 / 14$ & Sheep† & Malformed, aborted fetus & Negev & Brain & Not done & Not done \\
\hline 10 & $274 / 14$ & Sheep & Aborted fetus & Northern valley & Brain, placenta & Not done & Not done \\
\hline 11 & $2504 / 3 / 14$ & Sheep & Malformed, aborted fetus & Northern valley & Brain, placenta & Positive & Positive \\
\hline 12 & $275 / 1 / 14$ & Sheep & Malformed, aborted fetus & Northern valley & Brain, placenta & Negative & Negative \\
\hline 13 & $275 / 2 / 14$ & Sheep & Malformed aborted fetus & Northern valley & Brain, placenta & Not done & Not done \\
\hline 14 & $263 / 14$ & Goat & Malformed, aborted fetus & Northern valley & Brain, placenta & Not done & Not done \\
\hline 15 & $215 / 14$ & Cattle & Aborted fetus & Upper Galilee & Brain & Negative & Negative \\
\hline
\end{tabular}

activity. Thus, isolation of SHUV from malformed brains may indicate strong neurotropism of this putative pathogen. The possibility of its replication in the fetal nervous system should also be considered because an affected fetus that is born alive is likely a reservoir. Indeed, AKAV was identified in the hippocampus (only) of adult lactating cows (data not shown), and similar epidemiologic evidence might result from other Simbu virus infections.

A serologic survey conducted in Israel during the 2001-2003 outbreaks of AHS showed reactivity of AINV to serum samples of ruminants in Israel's southern regions (3). Because AINV and SHUV are known to have a strong serologic cross-reaction, SHUV has likely previously infiltrated Israel. However, whether the seroreactivity results from AINV or SHUV remains unresolved.

The emergence and reemergence of arboviruses should interest medical practitioners, particularly epidemiologists. The appearance of exotic viruses in unexpected locations might result in more severe pathology in newly invaded regions than in the original arbovirusendemic areas. Furthermore, SHUV has been detected in a child with febrile illness (2), a finding that suggests a potential zoonotic problem.

\section{References}

1. Inaba Y, Kurogi H, Omori T. Akabane disease: epizootic abortion, premature birth, stillbirth and congenital arthrogryposishydranencephaly in cattle, sheep and goats caused by Akabane virus. Aust Vet J. 1975;51:584-5. http://dx.doi.org/10.1111/ j.1751-0813.1975.tb09397.x

2. Causey OR, Kemp GE, Causey CE, Lee VH. Isolation of Simbu-group viruses in Ibadan, Nigeria 1964-69, including the new types Sango, Shamonda, Sabo and Shuni. Ann Trop Med Parasitol. 1972;66:357-62.

3. Brenner J, Tsuda T, Yadin H, Chai D, Stram Y, Kato T. Serological and clinical evidence of teratogenic Simbu serogroup virus infection of cattle in Israel, 2001-2003. Vet Ital. 2004;40:119-23.
4. van Eeden C, Williams JH, Gerdes TG, van Wilpe E, Viljoen A, Swanepoel R, et al. Shuni virus as cause of neurological disease in horses. Emerg Infect Dis. 2012;18:318-21. http://dx.doi.org/10.3201/eid1802.111403

Address for correspondence: Jacob Brenner, Kimron Veterinary Institute, Bet Dagan 50250, Israel; email: yakovb@moag.gov.il

\section{Genetic Characterization of Highly Pathogenic Avian Influenza A(H5N6) Virus, Guangdong, China}

\author{
Chris Ka Pun Mok, ${ }^{1}$ Wen Da Guan, ${ }^{1}$ \\ Xiao Qing Liu, ${ }^{1}$ Mart Matthias Lamers, ${ }^{1}$ \\ Xiao Bo Li, Ming Wang, Tami Jing Shu Zhang, \\ Qing Ling Zhang, Zheng Tu Li, Ji Cheng Huang, \\ Jin Yan Lin, Yong Hui Zhang, Ping Zhao, \\ Horace Hok Yeung Lee, Ling Chen, Yi Min Li, \\ Joseph Sriyal Malik Peiris, Rong Chang Chen, \\ Nan Shan Zhong, Zi Feng Yang
}

Author affiliations: The University of Hong Kong,HKU-Pasteur Research Pole, Hong Kong, China (C.K.P Mok, M.M. Lamers, T.J.S. Zhang, H.H.Y. Lee, J.S.M. Peiris); State Key Laboratory of Respiratory Disease, Guangzhou, China (W.D. Guan, X.Q. Liu, Q.L. Zhang, Z.T. Li, L. Chen, Y.M. Li, R.C. Chen, N.S. Zhong, Z.F. Yang); Guangdong Inspection and Quarantine Technology Center, Guangzhou (X.B. Li, J.C. Huang); Guangdong Center for Disease Control and Prevention, Guangzhou (J.Y. Lin, Y.H. Zhang); Guangzhou Center for Disease Control and

${ }^{1}$ These authors contributed equally to this article. 